\title{
The seismotectonics of western Skagerrak
}

\author{
Mathilde Bøttger Sørensen • Peter H. Voss • \\ Jens Havskov • Søren Gregersen · Kuvvet Atakan
}

Received: 25 February 2009 / Accepted: 8 March 2011 / Published online: 20 April 2011

(C) The Author(s) 2011. This article is published with open access at Springerlink.com

\begin{abstract}
The seismically active Skagerrak region in the border area between Denmark and Norway has traditionally been associated with uncertain earthquake locations due to the limited station coverage in the region. A new seismic station in southern Norway and a recent update of the earthquake database of the Danish National Network have led to a much more complete and homogeneous data coverage of the Skagerrak area, giving the possibility of improved earthquake locations in the region. In this study, we relocate earthquakes in the Skagerrak area to obtain a more exact picture of the seismicity and investigate well-recorded events to determine the depth distribution. Hypocenter depths are found to be generally in the range $11-25 \mathrm{~km}$. Furthermore, new composite focal mechanisms are determined for clusters of events with similar waveforms. Results indicate that the Skagerrak seismicity is associated with shallow, crustal faults oriented in the NS direction south of the Sorgenfrei-Tornquist
\end{abstract}

M. B. Sørensen $(\varangle)$ J J. Havskov · K. Atakan

Department of Earth Science, University of Bergen,

Allegt. 41, 5007 Bergen, Norway

e-mail: mathilde.sorensen@geo.uib.no

P. H. Voss · S. Gregersen

Geological Survey of Denmark and

Greenland - GEUS, Øster Voldgade 10,

1350 Copenhagen K, Denmark
Zone (STZ) as well as with the STZ itself. Mainly reverse faulting mechanisms along NESW oriented faults indicate maximum horizontal compression in the NW-SE direction. This is in agreement with World Stress Map generalizations, most likely associated with ridge push forces from the mid-Atlantic ridge, though modified probably by local crustal weaknesses.

Keywords Skagerrak - Seismotectonics • Seismicity - Fault plane solution • Hypocenter depth - Sorgenfrei-Tornquist zone

\section{Introduction}

The Skagerrak Sea is located between southern Norway and Denmark, connecting the North Sea to the Kattegat Sea further east. This area has long been known to be one of the most seismically active areas in Denmark (Lehmann 1956; Gregersen 1979; Gregersen et al. 1996a), which is generally a region of low seismicity. Especially the western part of Skagerrak, between southern Norway and northwestern Jutland has seismic activity. Due to the offshore locations of most of the western Skagerrak earthquakes in the border zone between two seismic networks (the Norwegian and the Danish National Seismic Networks), location uncertainties have been large 
(around $40 \mathrm{~km}$ ), and it is still not clear which geological structures are the origins of the events. The seismicity in the region was recognized by Gregersen (1979) as a general trend of events striking perpendicular to the coast of northwest Jutland, supplemented by a weak trend parallel to the Norwegian coast. He concluded that the events seem to locate close to the base of the crust at approximately $30-40 \mathrm{~km}$ depth. In later studies, Gregersen et al. (1996a, b) find no direct correlation to geologically known faults in the area. However, they recognize that the earthquakes occur along the central axis of the NorwegianDanish basin where Mesozoic and Paleozoic faults are present. Characteristic of both of these studies are the limited datasets available at the times of publication, both in terms of number of recorded events and station configuration.

Only six focal mechanisms have been published for the western Skagerrak area (Slunga et al. 1984; Fejerskov et al. 2000); hence, the basis for stress inversions is scarce. Published estimates of the orientation of maximum horizontal compression are in general agreement, varying between WNW-ESE (Hicks 1996; Hicks et al. 2000), NWSE (Gregersen 1992) and NNW-SSE (Reinecker et al. 2005). Available earthquake focal mechanisms show strike-slip, normal or oblique normal faulting with fault planes in agreement with the published stress orientations (Bungum et al. 1991; Dehls et al. 2000; Gregersen and Arvidsson 1992; Slunga et al. 1984). Some of the available focal mechanisms are considered unreliable (see discussion in a later section) and an important aim of this study is to update available mechanisms.

Many studies have discussed the stress regime and causes of seismicity in the Fennoscandian region based on e.g. focal mechanisms, isostatic uplift modelling and borehole break-out data (e.g. Bungum et al. 1991; Lindholm et al. 1995; Fjeldskaar et al. 2000; Hicks et al. 2000; Gregersen and Voss 2010; Bungum et al. 2010). In most of these studies, the western Skagerrak is on the border of the study area, and data coverage is scarce for this region. In a recent study, Bungum et al. (2009) focus on the 1904 M5.4 Oslofjord earthquake and derive a new location and magnitude estimate for this event. The paper furthermore provides an overview of previous seismotec- tonic studies with focus on the Oslo Rift, east of our study area. For that area, they observe that the maximum compressive stresses are oriented northwest-southeast in the direction of ridge push and that shallow earthquakes tend to have normal mechanisms whereas deeper ones have strike-slip or reverse mechanisms. Based on previous work (Byrkjeland et al. 2000), they stress that ridge push from the mid-Atlantic ridge alone is not sufficient to explain the seismicity in the Oslo Graben and state the importance of regional and local stress sources combined with crustal weaknesses. They interpret the relatively high seismicity level in the Oslo Graben to be associated with the crust being slightly weaker than the surroundings rather than locally elevated stress levels. They emphasize the general problem of associating large earthquakes with specific faults in Norway, but describe a correlation between earthquake occurrence and the density of mapped faults.

Since 2003, the short-period seismic station SNART in southern Norway (for location, see Fig. 1) has provided high-quality recordings of earthquakes in Skagerrak, leading to improved earthquake locations in the region. Furthermore, the earthquake database of the Danish National Seismic Network has recently been updated, old phase readings as well as readings from the Norwegian National Seismic Network have been included systematically and events have been reviewed and relocated. This has led to a much more complete and homogeneous data coverage of the Skagerrak area, giving the possibility of improved earthquake locations in the region.

Based on this improved dataset, in the present study, we relocate earthquakes in western Skagerrak to obtain new information about their relation to tectonics. Hypocentral depths are constrained using theoretical arrival times of the decisive phases and waveform modelling for especially well-recorded events, and new focal mechanisms are derived based on events with highquality records. Furthermore, a velocity model representative for the area is used to relocate all events in the study area. The improved locations and focal mechanisms are compared to the regional tectonics and thereby provide new information about the origin of the Skagerrak seismicity. 


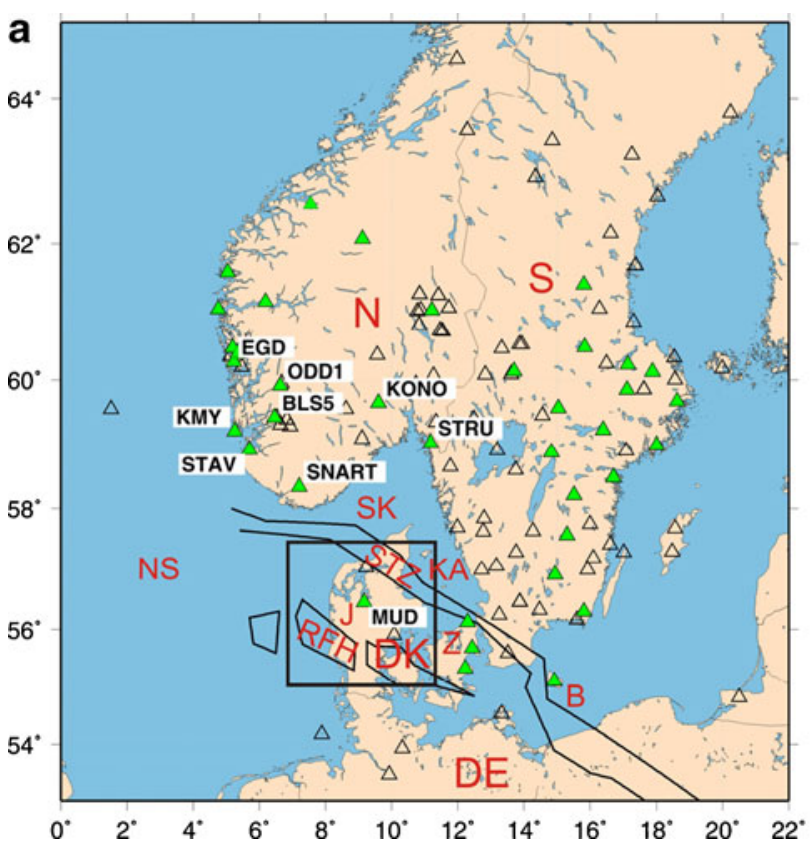

Fig. 1 a Overview map of southern Scandinavia, showing the locations of the main tectonic features in the Skagerrak area and seismic stations. Open triangles show stations used for locating all events in the time from 1980-today, green triangles are stations used for locating the 27 test events. Station codes are given for the stations used for deriving fault plane solutions. The black box indicates the approximate location of the schematics in (b). b Schematic illustration of the most important events in the development of the area of Denmark between the old shield in

\section{Tectonic setting}

The Skagerrak Sea is largely covered by sedimentary rocks of the same type as found in the hydrocarbon provinces of the North Sea. This implies a potential for hydrocarbon resources in Skagerrak, which has motivated numerous investigations aimed at studying the geological and tectonic evolution in this region (Lie and Andersson 1998; Lie and Husebye 1993, 1994; Longva and Thorsnes 1997). The shallower parts of the crust have been the main focus of these local as well as more regional studies (Scheck-Wenderoth and Lamarche 2005; Thybo 1997), and little information is available about deeper structures (Medhus et al. 2011).

The Skagerrak is located in a tectonically complex area, which has been formed through numerous events since Cambrian. The most important b

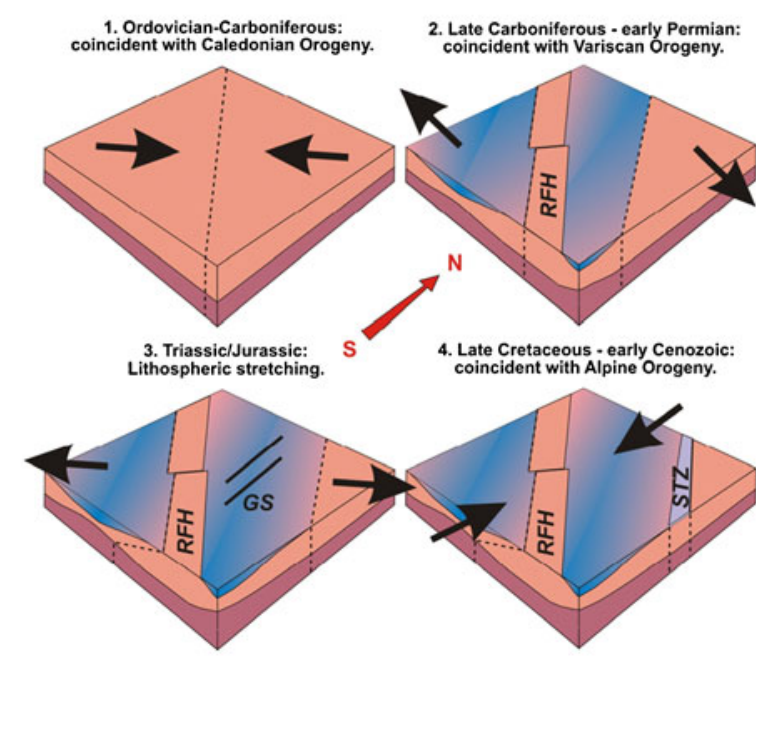

southern Norway and western Sweden and the younger crust in northern Germany. From STZ and southwards to RFH, the Norwegian-Danish Basin has developed. Skagerrak is part of this basin. South of RFH is the NorthGerman basin. Modified from Gregersen et al. (2006). $R F H$ Ringk $\varnothing$ bing-Fyn High; $S T Z$ Sorgenfrei-Tornquist Zone; $N$ Norway; $S$ Sweden; $D K$ Denmark; $D E$ Germany; $N S$ North Sea; SK Skagerrak; KA Kattegat; $J$ Jutland; $Z$ Zealand; $B$ Bornholm; $G S$ graben structures

events are illustrated in Fig. 1b. The Caledonian Orogeny during early Paleozoic time caused slight deformation, faulting, uplift and erosion (Longva and Thorsnes 1997). This was followed by early Permian rifting leading to the generation of NW-SE oriented basin structures such as the Norwegian-Danish, German and Polish Basins (comprising the Northern and Southern Permian Basins which are separated by the RingkøbingFyn High, Fig. 1). Late Permian and Mesozoic superposed extensional tectonics created NS oriented graben structures. During Late Cretaceous to Early Cenozoic, a phase of inversion dominated, followed by renewed subsidence during the Cenozoic (Scheck-Wenderoth and Lamarche 2005). As a consequence of this tectonic evolution, the area is today dominated by NW-SEoriented basins and younger NS-oriented graben structures. The Skagerrak Sea covers part of the 
Norwegian-Danish Basin. Another dominating tectonic feature is the Sorgenfrei-Tornquist Zone (STZ) striking through northern Denmark from the Skagerrak Sea to Bornholm in the SE. This is the northwesternmost segment of the Tornquist Zone, a fault zone extending from the Black Sea to Skagerrak, which has been active at least since Late Carboniferous (Berthelsen 1998; Erlström et al. 1997; Ziegler 1990). The STZ is associated with a significant change in thickness of the crystalline crust, which is thinner to the southwest of the zone (Lie and Andersson 1998; Thybo 1997; Grad and Tiira 2007). The investigated area borders towards northeast to the area which is dominated by the Oslo Graben. This developed in Carboniferous-Permian times overlapping with step 2 of Fig. 1 further south.

The present study focuses on the western part of Skagerrak, which is cut through by the STZ. Previous studies have indicated that the seismicity in this region is not associated with the STZ, contrary to the situation further southeast in the Kattegat Sea (Gregersen et al. 1996a, b). The eastern edge of the Oslo Graben area has experienced the largest earthquake of the southern Scandinavian area, the Oslofjord earthquake in 1904 (e.g., Bungum et al. 2009). This area is nowadays less active than that of the present investigation.

Several authors have compiled Moho depth data for the general region around the STZ based on seismic data (EUGENO-S Working Group 1988; Lie and Andersson 1998; ScheckWenderoth and Lamarche 2005; Thybo 1997; Tesauro et al. 2008; Grad and Tiira 2007). For the study area in Skagerrak, Moho depth estimates vary in the range $23-30 \mathrm{~km}$, increasing from northwestern Denmark towards northern Skagerrak.

\section{Seismicity in western Skagerrak}

For this study, all earthquakes after 1980 have been relocated with the depth fixed at $15 \mathrm{~km}$ (see discussion on depths in a later section) and using a new local velocity model (Table 1 ). This model was defined to represent an average of the structure under the central and northern part of Denmark (based on measurements of the
Table 1 Velocity model used for relocating earthquakes in Skagerrak

\begin{tabular}{ll}
\hline Depth to top of layer $(\mathrm{km})$ & $V_{\mathrm{p}}(\mathrm{km} / \mathrm{s})$ \\
\hline 0 & 6.2 \\
16 & 6.7 \\
30 & 8.05 \\
\hline
\end{tabular}

The model uses a $V_{p} / V_{s}$ ratio of 1.73

EUGENO-S Working Group (1988), noting the reviews by Thybo (2000) and by Pedersen et al. (1999)) and the very southern part of Norway (based on an approximation to the 2D model of Cassell et al. (1983)). The relatively low velocity in the upper layers of the Danish crust is not included in this model. This could be corrected for by applying a station correction of the order of $0.3 \mathrm{~s}$ to the P-wave arrival times at station MUD in the location procedure. However, records from station MUD have a relatively low signal-to-noise ratio, and readings are, therefore, in most cases associated with an uncertainty larger than the necessary station correction. For this reason, we have chosen not to include such a correction.

The updated database contains 414 events in our study area $\left(56-59^{\circ} \mathrm{N}, 6-10^{\circ} \mathrm{E}\right)$ in the time from 1980 until today, which are shown in Fig. 2. The relatively large scatter in the locations is most likely due to rather large location errors arising from an unfavorable station configuration with only few records available for most events. However, there seems to be a general trend of activity striking to the NW from northwestern Jutland, as well as a N-S-oriented belt of activity to the south of southern Norway. There does not seem to be any temporal clustering of the seismicity.

We expect the best locations in the database to be the ones based on phase readings from a large number of stations, and highlight therefore in Fig. 2 the locations of events which have been recorded on 10 or more stations. Ideally, use of phase readings should have been limited to stations within a limited distance (e.g. $300 \mathrm{~km}$ ) to reduce uncertainties caused by low signal-to-noise ratios and varying velocity structure. However, for the majority of events this would provide too few stations to obtain reliable locations. The highlighted events in Fig. 2 show a more distinct seismicity pattern with the general trends of activity aligned towards NW from northwestern Jutland 
Fig. 2 Instrumental earthquakes in the study area in the time 1980 to present plotted on top of known faults in the region (Vejbæk and Britze 1994). Events which have been recorded at a minimum of 10 stations and are, therefore, expected to have especially well-constrained locations are shown as dark red.

Events have been relocated using the velocity model in Table 1 with depths fixed at $15 \mathrm{~km}$

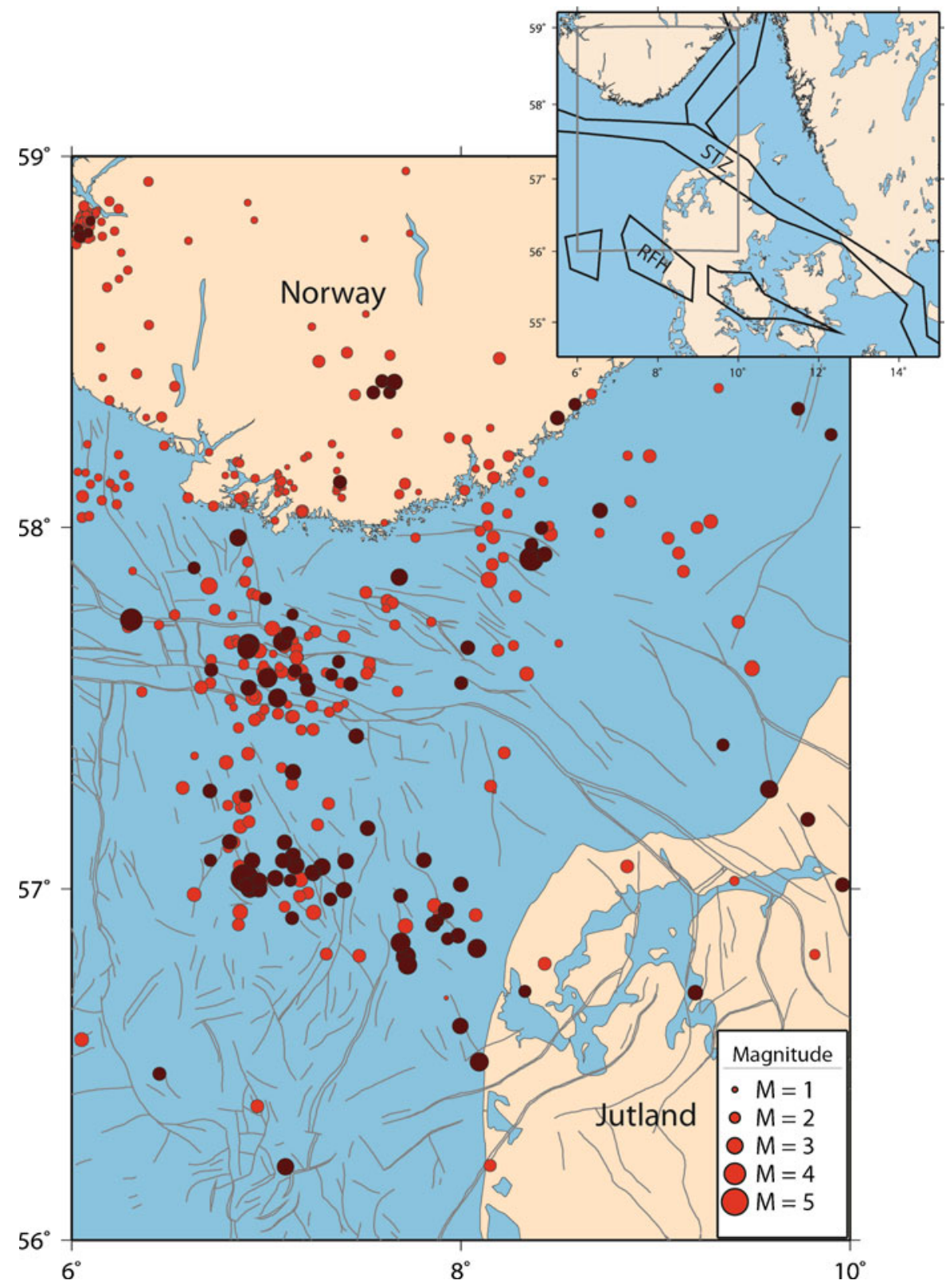

and southwards from southern Norway. Furthermore, there seems to be a patch of events in the STZ, around $57.5^{\circ} \mathrm{N}, 7^{\circ} \mathrm{E}$, and there is a cluster of events north of the STZ at around $58^{\circ} \mathrm{N}, 8.5^{\circ} \mathrm{E}$.

In order to investigate the nature of the Skagerrak seismicity in more detail, a test dataset of events recorded by the two nearest stations, MUD in Denmark and SNART in Norway (installed in 1977 and 2003, respectively; Fig. 1) was extracted from the database. These 27 test events (see Table 2 and Fig. 3) were investigated in detail to obtain information about the depths of the Skagerrak earthquakes and their focal mechanisms.

\subsection{Location of test events}

The initial locations of the 27 test events were obtained using phase readings from 4-19 stations, and this varying station configuration can bias 
Table 2 Earthquakes included in the test dataset

\begin{tabular}{|c|c|c|c|c|c|c|c|c|c|c|c|c|}
\hline$N$ & Year & Date & HRMM & $\mathrm{Sec}$ & Latitude & Error & Longitude & Error & NST & RMS & GAP & Ml \\
\hline 1 & 2003 & 102 & 0123 & 43.4 & 56.898 & 8 & 6.856 & 17 & 5 & 0.8 & 232 & 1.9 \\
\hline 2 & 2003 & 123 & 0034 & 46.5 & 58.002 & 6 & 8.338 & 13 & 16 & 1.0 & 142 & 2.5 \\
\hline 3 & 2004 & 226 & 0851 & 10.0 & 56.889 & 5 & 7.957 & 11 & 17 & 0.4 & 207 & 1.8 \\
\hline 4 & 2004 & 75 & 1809 & 36.6 & 57.509 & 8 & 7.141 & 23 & 5 & 0.8 & 198 & 2.2 \\
\hline 5 & 2005 & 223 & 0633 & 12.3 & 57.534 & 5 & 7.201 & 19 & 6 & 0.6 & 195 & 2.4 \\
\hline 6 & 2005 & 512 & 1806 & 39.7 & 57.659 & 8 & 7.032 & 29 & 5 & 1.0 & 195 & 2.0 \\
\hline 7 & 2005 & 513 & 0108 & 9.1 & 57.516 & 5 & 7.123 & 13 & 5 & 0.5 & 198 & 2.0 \\
\hline 8 & 2005 & 523 & 2351 & 6.7 & 57.625 & 9 & 7.240 & 30 & 8 & 0.9 & 190 & 2.5 \\
\hline 9 & 2005 & 613 & 0230 & 40.4 & 57.263 & 10 & 6.898 & 26 & 4 & 0.8 & 215 & 2.0 \\
\hline 10 & 2005 & 624 & 0330 & 9.8 & 57.631 & 7 & 7.033 & 15 & 3 & 0.5 & 323 & 1.7 \\
\hline 11 & 2005 & 723 & 1705 & 39.8 & 57.161 & 6 & 6.864 & 14 & 37 & 0.7 & 220 & 2.8 \\
\hline 12 & 2005 & 821 & 1622 & 7.5 & 57.145 & 13 & 7.406 & 40 & 16 & 0.6 & 223 & 2.4 \\
\hline 13 & 2005 & 1028 & 0722 & 24.9 & 57.642 & 10 & 6.797 & 23 & 8 & 0.7 & 202 & 3.8 \\
\hline 14 & 2005 & 1128 & 1718 & 13.8 & 57.529 & 5 & 7.265 & 13 & 5 & 0.4 & 194 & 1.6 \\
\hline 15 & 2006 & 110 & 0020 & 35.3 & 57.144 & 10 & 6.991 & 23 & 8 & 0.8 & 218 & 2.3 \\
\hline 16 & 2006 & 313 & 1250 & 57.2 & 57.414 & 3 & 9.321 & 14 & 11 & 0.6 & 181 & 2.4 \\
\hline 17 & 2006 & 525 & 1155 & 6.3 & 57.343 & 9 & 6.814 & 28 & 5 & 0.9 & 213 & 2.1 \\
\hline 18 & 2006 & 627 & 1921 & 35.7 & 57.236 & 11 & 6.906 & 30 & 5 & 0.9 & 216 & 2.3 \\
\hline 19 & 2006 & 925 & 1244 & 57.8 & 57.526 & 5 & 7.057 & 13 & 7 & 0.4 & 199 & 2.6 \\
\hline 20 & 2007 & 21 & 0211 & 25.0 & 56.928 & 11 & 7.097 & 24 & 7 & 0.7 & 226 & 2.2 \\
\hline 21 & 2007 & 22 & 1437 & 35.4 & 56.992 & 5 & 7.166 & 12 & 13 & 0.5 & 221 & 3.0 \\
\hline 22 & 2007 & 221 & 0430 & 8.4 & 56.832 & 12 & 6.967 & 25 & 14 & 0.8 & 234 & 2.7 \\
\hline 23 & 2007 & 421 & 0815 & 1.5 & 56.335 & 9 & 6.959 & 14 & 6 & 0.5 & 260 & 2.4 \\
\hline 24 & 2007 & 721 & 1514 & 6.9 & 56.924 & 6 & 7.029 & 14 & 18 & 0.5 & 228 & 3.0 \\
\hline 25 & 2007 & 928 & 2156 & 7.9 & 57.018 & 13 & 6.895 & 32 & 11 & 1.0 & 226 & 2.5 \\
\hline 26 & 2008 & 124 & 1851 & 52.8 & 57.563 & 11 & 7.094 & 15 & 16 & 0.9 & 197 & 3.0 \\
\hline 27 & 2008 & 23 & 1452 & 32.0 & 57.463 & 5 & 7.593 & 15 & 8 & 0.7 & 187 & 2.4 \\
\hline
\end{tabular}

The hypocentral depths have been fixed to $15 \mathrm{~km}$

$N$ event ID, HRMM hour and minutes of origin time, Sec seconds of origin time, Error error estimate of location, NST number of stations used in location, RMS RMS error of location, GAP maximum azimuthal gap between stations used in location, $M l$ Local magnitude

the epicenter locations since station residuals will vary between stations and varying station configurations will affect the locations differently, partly because of an inhomogeneous velocity structure. In order to have minimum bias, a distance weighting scheme was applied so that stations within $200 \mathrm{~km}$ were given full weight, and the weight decreased linearly to 0 at $350 \mathrm{~km}$ epicentral distance. The hypocentral depths were fixed to $15 \mathrm{~km}$, based on the analysis described in the next section. The hypocenters are listed in Table 2 and shown in Fig. 3. Table 2 also gives the estimated epicentral errors. It is seen that the estimated errors in the latitude (NS direction) are typically less than $10 \mathrm{~km}$ while for longitudes (EW direction) they are typically less than $25 \mathrm{~km}$. This difference is due to the station geometry. It is also seen that the azimuthal gap is larger than $180^{\circ}$ for all events (except for one event, \#2) leading to the large estimated errors, particularly in the EW direction. The estimated errors are strongly dependent on number of stations and RMS of travel time residuals, particularly when few station are used. The events with the smallest RMS generally also have the lowest estimated errors since the values of the residuals are used to calculate the error estimate. For events with seven or more stations, the error estimates are generally less than $10 \mathrm{~km}$ in the NS direction and $20 \mathrm{~km}$ in the $\mathrm{EW}$ direction.

Some of the test events have remarkably similar waveforms, indicating that they originate from similar locations. It was, therefore, decided to group the events based on visual inspection of waveform similarity and/or distance from SNART (Fig. 4). Only the waveforms recorded at SNART were of sufficient quality to do such a grouping. 
Fig. 3 Earthquakes recorded at MUD and SNART, comprising the test dataset, plotted on top of known faults in the region (Vejbæk and Britze 1994). Numbers refer to Table 2. Focal mechanisms derived in this study are shown with the direction of maximum horizontal compression indicated (determined following the guidelines for the World Stress Map (Zoback 1992)). Black arrows indicate the direction of maximum horizontal compression for the composite solution based on all events (All, see text for details). The events have been relocated with the velocity model in Table 1 , excluding data from stations at distances larger than $350 \mathrm{~km}$ and fixing the depth at $15 \mathrm{~km}$. The groups defined in Fig. 4 are distinguished with color codes, Pub represents the focal mechanism solutions from the literature (Table 4)

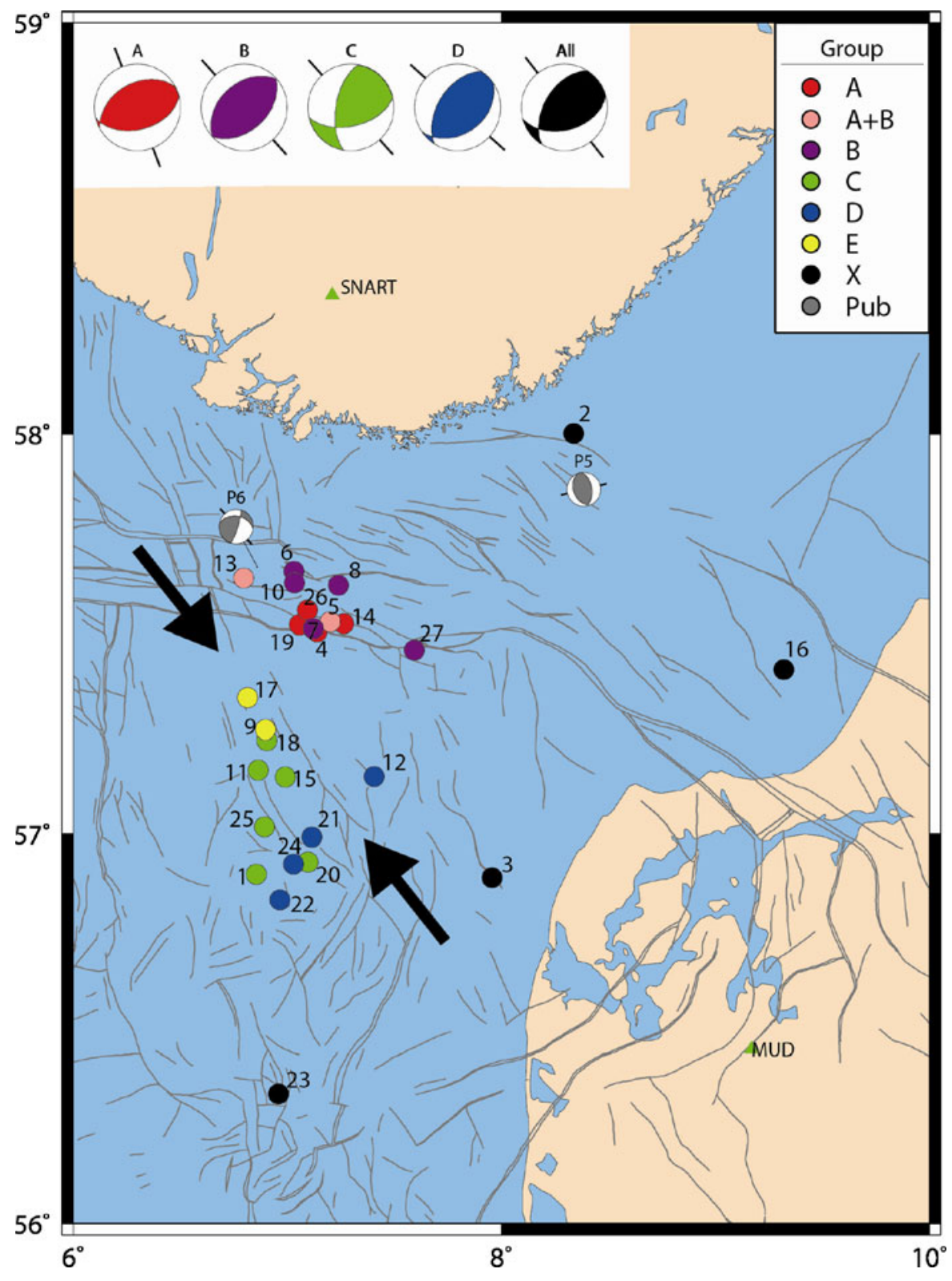

Groups A, B, C, D and E represent clusters of events which are located in the same area and have similar waveforms. Group $\mathrm{A}+\mathrm{B}$ are events located near groups $\mathrm{A}$ and $\mathrm{B}$ but with different looking waveforms. Group X contains the events with waveforms not fitting any other event and located far from the other groups. As can be seen from Fig. 4, especially the five events in group B $(6,7,8,10$ and 27), the last three events in group D (21, 22 and 24) and the last two events in group A (19 and 26) have similar waveforms.
We investigate here implications of this waveform similarity on the location errors for the events in group B. These events are very similar (the first two occur within $12 \mathrm{~h}$ ), particularly the first four $(6,7,8,10)$ and should have epicenters close to each other (within less than $5 \mathrm{~km}$ ). In the NS direction, the epicenters of these four events are within $17 \mathrm{~km}$, whereas in the EW direction, they are within $13 \mathrm{~km}$. The error estimates are $6-8 \mathrm{~km}$ in the NS and 15-28 km in the EW direction, indicating that the formal EW error estimates may 

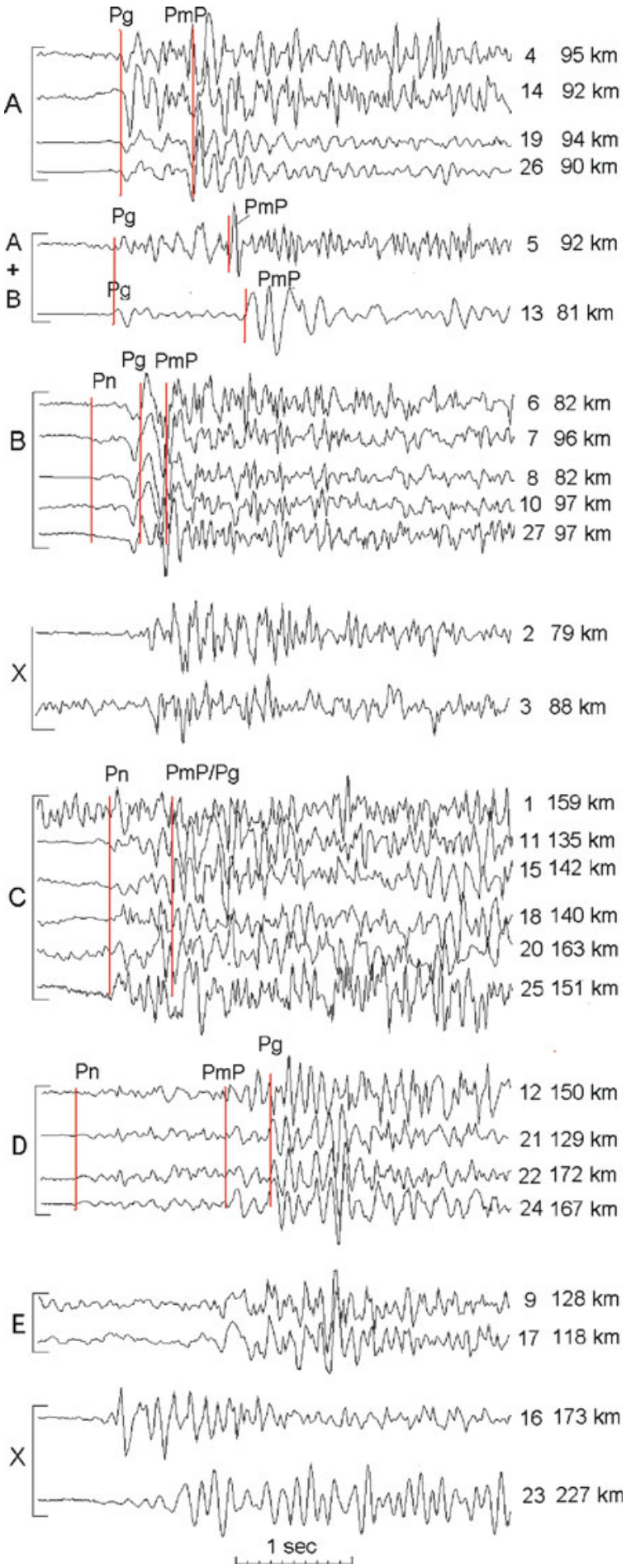

Fig. 4 The first few seconds of the P-wave train at station SNART for the test events compared to theoretical arrival times of the phases Pn, Pg and PmP calculated for the bestfitting depth (see text for details). Earthquake numbers (Table 2) and epicentral distances are given to the right be overestimated. Considering the $\mathrm{S}-\mathrm{P}$ times from SNART, the epicentral distances are expected to be within $1 \mathrm{~km}$ for the first four events, and using the back-azimuth from SNART and locating only with this station, the locations are found to be within $7 \mathrm{~km}$ in the EW direction. It is likely that the first four events of group B are indeed within $1 \mathrm{~km}$ of each other and represent a cluster of events. Using the same single station location procedure, event 27 is within $10 \mathrm{~km}$ of the other four events. This analysis clearly illustrates the problems associated with determining accurate hypocenters for this area.

\subsection{Depth of events}

The majority of earthquakes in southern Norway occur at depths of around $15 \mathrm{~km}$ (Havskov and Bungum 1987), whereas in Denmark there are few reliable depths available. On Zealand in eastern Denmark, depths of $20 \mathrm{~km}$ have recently been determined through modelling (Larsen et al. 2008), while in northern Jutland there are no reliable depth estimates. For the events in Skagerrak, the stations are too far from the events to reliably determine depth by normal earthquake location methods and only for stations SNART and MUD there are some events with station-event distances of less than $100 \mathrm{~km}$ (around $80-100 \mathrm{~km}$ ). We estimated earthquake depths for some of the 27 events recorded at SNART and MUD using the velocity model in Table 1 and considering records from SNART. Unfortunately, station MUD was either too far away from the events or the phase arrivals were too unclear to be used in the analysis, and the following analysis has, therefore, been based on recordings from SNART only. Considering that the data available are not sufficient to determine exact depths, our aim is to obtain a general estimate of the depth of events in the region and their uncertainties.

We first consider again the groups of events with similar waveforms, presented in Fig. 4, assuming that similar P-trains indicate similar depth. For each group, the theoretical arrival times of Pn, $\mathrm{Pg}$ and PmP for different depths were calculated and compared to the records of events within the group to estimate the event depths. The best fitting arrival times are included in Fig. 4. For 
group A, there is a very clear Moho reflection (Fig. 4), which is best fit by a depth of $16 \mathrm{~km}$. For group B, at a similar distance range as group A, the Moho reflection is not clearly seen. However, interpreting the weak first arrivals as Pn and the large phase arrival just after the $\mathrm{Pg}$ as $\mathrm{PmP}$, a depth of $25 \mathrm{~km}$ is obtained. Event 13 is the largest event, located in the same area as groups A and $\mathrm{B}$ but with different looking waveforms. It has a very clear Moho reflection, and the depth is determined to be $11.5 \mathrm{~km}$ (see also Fig. 5 and the discussion below). Event 5 is also in the area of groups A and B but has a less clear Moho reflection. For this event, the depth is determined to $12.5 \mathrm{~km}$. Events 2 and 3 are far from the other groups. They have unclear phases; therefore, no attempt has been made to determine depth. For the events in groups C, D and E, Pn arrives before $\mathrm{Pg}$ and $\mathrm{Pg}$ and $\mathrm{PmP}$ are close together. The depth is rather insensitive to the $\mathrm{Pn}-\mathrm{PmP} / \mathrm{Pg}$ arrival time difference. For the events in group $\mathrm{C}$, the depth has been estimated to $16 \mathrm{~km}$ and for the events in group D, $12 \mathrm{~km}$ was obtained. Both of these depths are uncertain. Events in group E look similar to the events in group $\mathrm{D}$; however, the $\mathrm{P}$ is not clear and therefore no attempt has been made

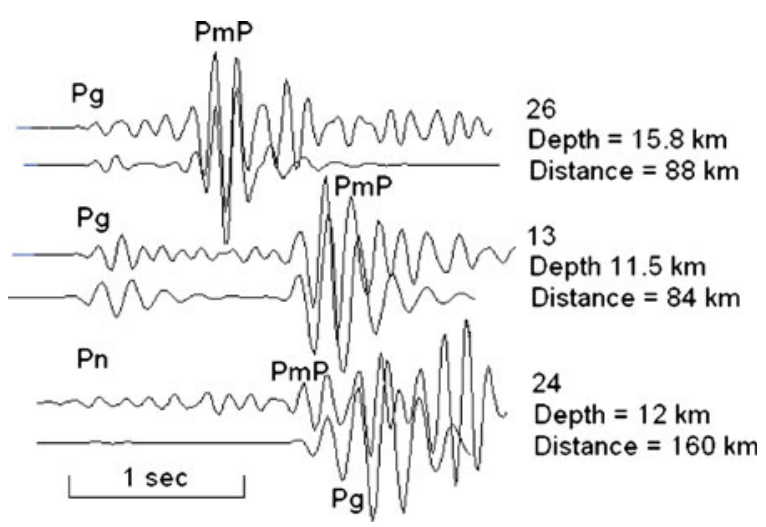

Fig. 5 Example of WKBJ modelling for estimating event depth for three events using the vertical component on station SNART. The traces are filtered between $5-10 \mathrm{~Hz}$ and shown in displacement. Event numbers, depths and distances are indicated to the right. The synthetic traces are the bottom traces. Theoretical phases arrivals are indicated. It is seen that the PmP arrivals are clearly identified in the recorded seismograms of events 26 and 13 while for event 24 , at a larger distance, the uncertainty in the phase identification is larger to determine depth. Events 16 and 23 (group X) are located far from SNART and have uncertain $\mathrm{P}$ arrivals, and no depth estimate was made.

Another way of estimating the event depths is thought waveform modelling. Acknowledging the limitations associated with data quality, we have selected the best recorded events to provide an estimate of the general depth distribution of events in the region. Theoretical phase arrival times and waveforms were calculated using the WKBJ method (Chapman and Orcutt 1985). Three examples are shown in Fig. 5, where theoretical arrival times are compared to the recorded waveforms for three events at different distances to SNART. It is seen that for events 13 and 26, the modelling results are convincing, while for event 24 , it is more uncertain. For each event, a fault plane solution was derived which provided the best possible fit to the recorded data and used in the modelling. These solutions may not be the only possible solutions, but as their main function is to assure that the radiation pattern fits at station SNART, they are considered sufficient for this modelling. The event depths obtained fit well with the depths estimated for the event clusters in Fig. 4. Considering the good fit to the observed waveforms, the uncertainties in these estimated depths are expected to be small. For example, the modelling of event 26 has a sensitivity to depth indicating that the obtained depth is accurate to $\pm 0.5 \mathrm{~km}$. However, the real depth uncertainty is larger due to model uncertainty which is not included in the modelling. Local structure deviations from the 1D model could give a bias in the depth, depending on the distance to station SNART.

In conclusion, the obtained depths are in the range $11-25 \mathrm{~km}$, with the most reliable concentrated in the range $11-16 \mathrm{~km}$. This is in agreement with the observations from southern Norway. Based on this, a depth of $15 \mathrm{~km}$ has been assumed for all events when relocating the database and determining fault plane solutions.

\subsection{Fault plane solutions}

The station distribution and signal-to-noise ratio made it impossible to determine fault plane 
Table 3 Composite fault plane solutions from this study

\begin{tabular}{llllllllll}
\hline Group & Strike & Dip & Rake & ErrF & ErrA & Npol & Nratio & Max bad pol & Max ratio \\
\hline A & 241 & 43 & 79 & 36 & 32 & 7 & 17 & 2 & 0.35 \\
B & 229 & 42 & 91 & 18 & 28 & 8 & 17 & 0 & 0.31 \\
C & 77 & 55 & 144 & 27 & 28 & 15 & 17 & 5 & 0.40 \\
D & 212 & 53 & 76 & 33 & 30 & 9 & 16 & 1 & 0.36 \\
All & 75 & 47 & 123 & 22 & 14 & 51 & 96 & 18 & 0.50 \\
\hline
\end{tabular}

Group group of events according to Fig. 4, All is all events, ErrF error in normal to fault plane, ErrA error in normal to auxilary plane, $\mathrm{Npol}$ number of polarities used, Nratio number of amplitude ratios, Max bad pol maximum number of non-fitting polarities, Max ratio maximum average $\log _{10} \mathrm{~S} / \mathrm{P}$ amplitude ratio error accepted

solutions based on polarity only, since for most events only 1-3 polarities could be read. Amplitude ratios of $\mathrm{Pg} / \mathrm{Sg}$ were, therefore, included from several stations in Norway (SNART, KMY, BLS5, KONO, EGD, STAV and ODD1; Fig. 1) as well as from station MUD when possible. First arrivals were often not $\mathrm{Pg}$ or $\mathrm{Sg}$, so the largest amplitudes were read in the P- and S-wave trains near the start of the wave train. Pg was read on the Z-component and $\mathrm{Sg}$ on the T-component. The depths were all fixed to $15 \mathrm{~km}$. Even with amplitude ratios, there was in general too little data to make reliable solutions for individual events, and it was, therefore, decided to make composite fault plane solutions for each of the groups A-D as well as for all the events jointly. Fault plane solutions were determined using the HASH programme (Hardebeck and Shearer 2002, 2003). The search for solutions with HASH is constrained by a maximum average amplitude ratio error and a number of polarity errors, which are increased by a given factor in each search until a sufficient number of solutions is obtained (usually several hundred). In this way, a large number of solutions are always obtained, and a most likely solution is calculated together with an estimate of the error. The solutions were found through a grid search using a grid of $2^{\circ}$, and the average $\log _{10} \mathrm{~S} / \mathrm{P}$ amplitude ratio errors found by HASH were less than 0.5 for a reasonable number of solutions (Table 3 ). For event 26 (group A), data from the Swedish station STRU was also used in the analysis. The obtained solutions are presented in Table 3 and in Fig. 3, where also the corresponding maximum compressive horizontal stress orientations are indicated.

The obtained solutions and the input data are shown in Fig. 6. All solutions are entirely
Fig. 6 Composite fault plane solutions shown on the lower focal sphere. Blue dots are dilatations, red dots compressions and the black dots are amplitude ratios. For the solution using all data, the amplitude data is not shown as it would make the figure unreadable. Note also that some polarities/amplitude ratios plot on top of each other, so that for example not all the 52 polarities used for deriving the solution based on all events are seen on the figure

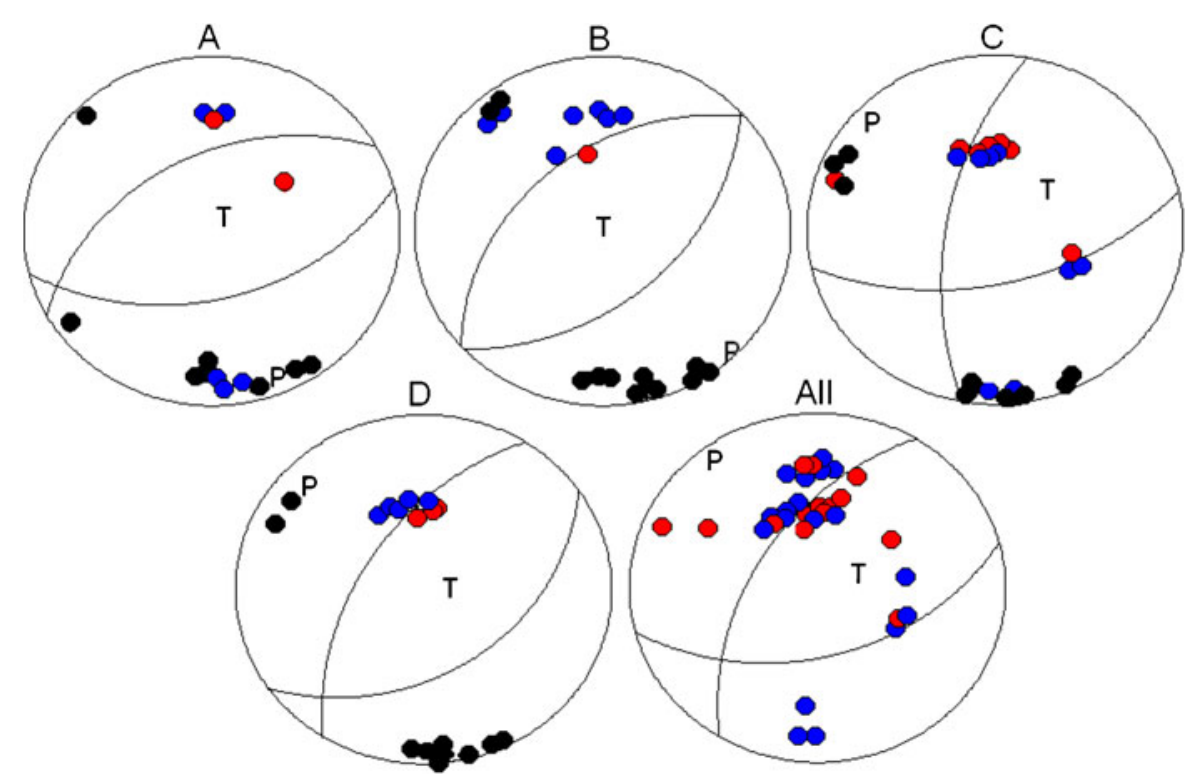


Table 4 Published focal mechanisms for the study area

\begin{tabular}{|c|c|c|c|c|c|c|c|c|c|}
\hline \# & OT & Lat & Lon & $\mathrm{h}$ & $\mathrm{M}_{\mathrm{L}}$ & Strike & Dip & Rake & Source \\
\hline$\overline{\mathrm{P} 1}$ & 197912250241 & 56.71 & 8.67 & 45 & 2.6 & 84 & 108 & 1 & Slunga et al. (1984) \\
\hline $\mathrm{P} 2$ & 198104171857 & 57.82 & 7.18 & 13 & 2.2 & 17 & 140 & -4 & , \\
\hline P3 & 198109071403 & 57.14 & 7.36 & 15 & 2.7 & 103 & 87 & -12 & , \\
\hline P4 & 198205240310 & 56.82 & 8.18 & 55 & 3.3 & 104 & 126 & -86 & , \\
\hline \multirow[t]{2}{*}{ P5 } & 198901200933 & 57.87 & 8.37 & 29 & 3.9 & 216 & 28 & 96 & Bungum et al. (1991) \\
\hline & Revised (see text) & & & & & 159 & 38 & 80 & \\
\hline P6 & $1990022620: 30$ & 57.67 & 6.86 & 3 & 3.1 & 18 & 82 & 50 & Lindholm et al. (2000) \\
\hline
\end{tabular}

OT Origin time (yyyy mmdd hhmm), Lat latitude, Lon longitude, $h$ depth $(\mathrm{km})$, Revised revised solution made in this study (see text for details)

dependent on the use of amplitude ratios, and no solutions can be made without. The distribution of data on the focal sphere is shown in the figure and as it is seen, many observations are close to each other. This is not an ideal situation, but the best which is possible with the current data. Consequently, the estimated errors are rather high (Table 3).

We have examined the previously published fault plane solutions for the region (Table 4) in order to combine them with our solutions. There are four solutions available from Slunga et al. (1984). These were made with absolute amplitudes using data from a temporary network with stations mostly in Sweden. Only one event, based on the output from the original analysis, had a reliable solution, the other three had too many very different solutions fitting the data. However, for the remaining event on 24 May, 1982 (03:10, $\mathrm{M}=3.3$ ) the focal mechanism was based on a depth of $55 \mathrm{~km}$ which is completely unrealistic; therefore, this solution was also discarded (the original data was not available for checking the solution).

Two additional solutions are available from other sources. The event on 20 January 1989 (9:33, $\mathrm{M}_{\mathrm{L}}=3.9$; Bungum et al. 1991) was reevaluated, and including four amplitude ratios (including the nearest station MUD), a new solution was obtained. For the other event (26 February, 1990, 20:30, $\mathrm{M}_{\mathrm{L}}=3.1$; Lindholm et al. 2000) no original data could be obtained, but the solution was derived in a similar manner as for the 1989 event (Lindholm, personal communication 2008), and it was decided to include it in the dataset.

\section{Discussion and conclusions}

The improved locations of the western Skagerrak earthquakes have led to a clearer image of the seismicity in the region. Arrival time modelling for the best-recorded events clearly shows that the events occur on shallow crustal faults, most likely at depths of $11-25 \mathrm{~km}$, where the best located events are in the $11-16 \mathrm{~km}$ range.

The location uncertainty is of the order of 10 $15 \mathrm{~km}$ for the best located events and smallest in the NS direction due to the station geometry. This uncertainty does not allow us to associate the individual earthquakes to specific faults; however, it is sufficiently to identify specific zones where activity is concentrated. A comparison of the relocated seismicity described in the previous sections to mapped faults in the region (Figs. 2 and 3) indicates that there is ongoing activity along the NS-oriented fault structures south of the STZ and that the STZ itself is most likely active as well. The indication of activity in the STZ, which has the physical dimensions required to potentially generate also larger earthquakes, calls for further investigation of this structure and its seismic potential.

The derived composite focal mechanisms with mainly reverse faulting indicate a remarkably consistent regional stress pattern with maximum compression in the NWbN-SEbS direction (Fig. 3). A similar stress orientation is indicated for the previously published fault plane solution of Lindholm et al. (2000; P6), whereas the modified solution of Bungum et al. (1991, P5) indicates a more E-W oriented stress pattern. The P5 solution, however, is located far east of the other events considered, 
and can be influenced by local stress sources or crustal weaknesses.

The dominating stress orientation, as determined for the composite fault plane solution based on all events, has been indicated by large arrows in Fig. 3. Comparing this stress orientation with the stress pattern obtained for the surrounding areas by Hicks et al. (2000), there is a general agreement. Hicks et al. (2000) find that the maximum horizontal compression is oriented in the ENE-WSW direction in the southern North Sea and onshore western Norway, whereas the orientation obtained for the Oslo graben is more in accordance with our results. Hicks et al. (2000) attribute the ENE-WSW stress orientation mainly to ridge push forces, and expect the rotation of the stress field in the Oslo Graben to be due to second-order stress sources. This is in agreement with the observations of Bungum et al. (2009) that other local and regional sources of stress are needed together with crustal weaknesses to explain the seismicity pattern in the Oslo Graben.

The presented investigation of the Skagerrak seismicity confirms that the regional stress field is dominated by ridge push forces from the mid-Atlantic ridge, moderated locally (Gregersen 1992; Hicks et al. 2000; Heidbach et al. 2007; Bungum et al. 2009) by other stress sources and geological structure weaknesses.

Acknowledgements The Norwegian National Seismic Network is operated by the Department of Earth Science, University of Bergen, Norway and supported by Oljeindustriens Lands Forening (OLF) and the Faculty of Mathematics and Natural Sciences, University of Bergen. The Danish National Seismic Network is operated by the Geological Survey of Denmark and Greenland. We thank University of Uppsala for providing phase readings and waveform data from the Swedish National Seismic Network.

Open Access This article is distributed under the terms of the Creative Commons Attribution Noncommercial License which permits any noncommercial use, distribution, and reproduction in any medium, provided the original author(s) and source are credited.

\section{References}

Berthelsen A (1998) The Tornquist zone northwest of the Carpathians: an intraplate pseudostructure. Geol Fören Stockh Förh 120:223-230
Bungum H, Alsaker A, Kvamme LB, Hansen RA (1991) Seismicity and Seismotectonics of Norway and nearby continental shelf areas. J Geophys Res 96:2249-2265

Bungum H, Pettenati F, Schweitzer J, Sirovich L, Faleide JI (2009) The 23 October 1904 Ms5.4 Oslofjord Earthquake: reanalysis based on macroseismic and instrumental data. Bull Seismol Soc Am 99(5):2836-2854

Bungum H, Olesen O, Pascal P, Gibbons S, Londholm C, Vestøl O (2010) The what extent is the present day seismicity in Norway driven by post-glacial rebound? J Geol Soc (Lond) 167:373-384

Byrkjeland U, Bungum H, Eldholm O (2000) Seismotectonics of the Norwegian continental margin. J Geophys Res 105:6221-6236

Cassell BR, Mykkeltveit S, Kanestrøm R, Husebye ES (1983) A North Sea southern Norway seismic crustal profile. Geophys J R Astron Soc 72:733-753

Chapman CH, Orcutt JA (1985) The computation of body wave synthetic seismograms in laterally homogeneous media. Rev Geophys 23:105-163

Dehls JF, Olesen O, Bungum H, Hicks EC, Lindholm CD, Riis F (2000) Neotectonic map: Norway and adjacent areas. Geological Survey of Norway, Sluppen

Erlström M, Thomas SA, Deeks N, Sivhed U (1997) Structure and tectonic evolution of the Tornquist Zone and adjacent sedimentary basins in Scania and the southern Baltic Sea area. Tectonophysics 271:191-215

EUGENO-S Working Group (1988) Crustal structure and tectonic evolution of the transition between the Baltic Shield and the North German Caledonides (The EUGENO-S Project). Tectonophysics 150:253-348

Fejerskov M, Lindholm C, Myrvang A, Bungum H (2000) Crustal Stress in and around Norway: a compilation of in situ stress observations. In: Nøttvedt A et al (eds) Dynamics of the Norwegian Margin. Geological Society, London, Special Publications, vol 167, pp 327-378

Fjeldskaar W, Lindholm C, Dehls JF, Fjeldskaar I (2000) Postglacial uplift, neotectonics and seismicity in Fennoscandia. Quat Sci Rev 19:1413-1422

Grad M, Tiira T (2007) The Moho depth of the European plate. http://www.seismo.helsinki.fi/mohomap and http://www.igf.fuw.edu.pl/mohomap2007

Gregersen S (1979) Earthquakes in the Skagerrak recorded at small distances. Bull Geol Soc Den 28:5-9

Gregersen S (1992) Crustal stress regime in Fennoscandia from focal mechanisms. J Geophys Res 97:1182111827

Gregersen S, Arvidsson R (1992) Atlas map 5, focal mechanisms. In: Blundell D, Freeman R, Mueller S (eds) A continent revealed: the european geotraverse. Cambridge University Press, Cambridge

Gregersen S, Voss P (2010) Irregularities in Scandinavian postglacial uplift/subsidence in time scales, tens, hundreds, thousands of years. J Geodyn 50:27-31

Gregersen S, Hjelme J, Hjortenberg E (1996a) Earthquakes in Denmark. Bull Geol Soc Denmark 44:115127

Gregersen S, Leth J, Lind G, Lykke-Andersen H (1996b) Earthquake activity and its relationship with geologically recent motion in Denmark. Tectonophysics 257:265-273 
Gregersen S, Voss P, Shomali ZH, Grad M, Roberts RG \& TOR Working Group (2006) Physical differences in the deep lithosphere of northern and Central Europe. Geol Soc, London, Memoirs 32:313-322. doi:10.1144/GSL.MEM.2006.032.01.18

Hardebeck JL, Shearer PM (2002) A new method for determining firstmotion focal mechanisms. Bull Seismol Soc Am 92:2264-2276

Hardebeck JL, Shearer PM (2003) Using S/P amplitude ratios to constrain the focal mechanisms of small earthquakes. Bull Seismol Soc Am 93:2434-2444

Havskov J, Bungum H (1987) Source parameters for earthquakes in the northern North Sea. Nor Geol Tidsskr 67

Heidbach O, Reinecker J, Tingay M, Müller B, Sperner B, Fuchs K, Wenzel F (2007) Plate boundary forces are not enough: second- and third-order stress patterns highlighted in the World Stress Map database. Tectonics 26:TC6014. doi:10.1029/2007TC002133

Hicks EC (1996) Crustal stresses in Norway and surrounding areas as derived from earthquake focal mechanism solutions and in-situ stress measurements. Cand. Scient., University of Oslo

Hicks EC, Bungum H, Lindholm CD (2000) Stress inversion of earthquake focal mechanism solutions from onshore and offshore Norway. Nor Geol Tidsskr 80:235-250

Larsen TB, Gregersen S, Voss PH, Bidstrup T, OrozovaBekkevold V (2008) The earthquake that shook central Sjælland, Denmark, November 6, 2001. Bull Geol Soc Denmark 56:1-11

Lehmann I (1956) Danish earthquakes. Medd Geol Soc Den 13:88-103 (in Danish)

Lie JE, Husebye ES (1993) Seismic imaging of upper crustal basement faults in the Skagerrak Sea. Tectonophysics 219:119-128

Lie JE, Husebye ES (1994) Simple-shear deformation of the Skagerrak lithosphere during the formation of the Oslo Rift. Tectonophysics 232:133-141

Lie JE, Andersson M (1998) The deep-seismic image of the crustal structure of the Tornquist Zone beneath the Skagerrak Sea, northwestern Europe. Tectonophysics 287:139-155

Lindholm CD, Bungum H, Bratli RK, Aadnøy BS, Dahl N, Tørudbakken B, Atakan K (1995) Crustal Stress in the northern North Sea as inferred from borehole breakouts and earthquake focal mechanisms. Terra Nova 7:51-59
Lindholm C, Bungum H, Hicks E, Villagran M (2000) Crustal stress and tectonics in Norwegian regions determined from earthquake focal mechanisms. Geol Soc London, Special Publications 167:429-439

Longva O, Thorsnes T (1997) Skagerrak in the past and the present-and integrated study of geology, chemistry, hydrogeography and microfossil ecology. Nor Geol Unders 8:100

Medhus AB, Balling N, Jacobsen BH, Weidle C, Voss P, England RW, Kind R, Thybo H (2011) Upper mantle structure beneath the southern Scandes Mountains and the northern Tornquist Zone revealed by $\mathrm{P}$-wave travel time tomography. Geophys J Int (in revision)

Pedersen T, Gregersen S, Tor Working Group (1999) Project Tor: deep lithospheric variation across the Sorgenfrei-Tornquist Zone, southern Scandinavia. Bull Geol Soc Den 46:13-24

Reinecker J, Heidbach O, Tinagy M, Sperner B, Müller B (2005) The release 2005 of the World Stress Map. Available online at www.world-stress-map.org

Scheck-Wenderoth M, Lamarche J (2005) Crustal memory and basin evolution in the Central European Basin System-new insights from a 3D structural model. Tectonophysics 297:143-165

Slunga R, Norrman P, Glans A-C (1984) The seismicity of southern Sweden. FOA Report C20545-T1, National Defense Research Institute

Tesauro M, Kaban MK, Cloetingh SAPL (2008) EuCRUST-07: a new reference model for the European crust. Geophys Res Lett 35:L05313. doi: 10.1029/2007GL032244

Thybo H (1997) Geophysical characteristics of the Tornquist Fan area, northwest Trans-European Suture Zone: indication of late Carboneferous to early Permian dextral transtension. Geol Mag 134: 597-606

Thybo H (2000) Crustal structure and tectonic evolution of the Tornquist fan region as revealed by geophysical methods. Bull Dan Geol Soc 46:145-160

Vejbæk OV, Britze P (1994) Geological map of Denmark 1: 750 000, top pre-Zechstein. Geological Survey of Denmark, Map series No. 45

Ziegler PA (1990) Geological atlas of western and Central Europe. Elsevier, The Hague, Shell International Petrolium Maatschappij/Amsterdam

Zoback ML (1992) First- and second-order patterns of stress in the lithosphere: the world stress map project. J Geophys Res 97:11703-11728 